\title{
Building energy modelling and simulations: qualitative and quantitative analysis
}

\author{
Robert Gajewski ${ }^{1, *}$, Pawet Pieniążek ${ }^{1}$ \\ ${ }^{1}$ Warsaw University of Technology, Faculty of Civil Engineering, Al. Armii Ludowej 16, \\ Warsaw 00-637, Poland
}

\begin{abstract}
Buildings consume half of all energy use and are also responsible for a similar proportion of carbon dioxide emission. The heat transfer across the building envelope - the shell of a house that separates the inside and outside, should generally be minimized. In the paper validation and verification based on Building Energy Simulation Test (BESTEST) of Energy3D computer code is presented. Program proved to be an excellent tool for qualitative and quantitative analysis of buildings.
\end{abstract}

\section{Introduction and literature review}

Buildings consume between $40 \%$ and $60 \%$ of all energy use. They are also responsible for a similar proportion of humankind's carbon dioxide emissions. In the first part of twentieth century, calculations of the thermal response of buildings have made an assumption that the boundary conditions and the whole problem are static. Thus a fictitious steady-state problem was defined in order to perform energy calculations. Now building energy modelling is mainly based on CFD (Computational Fluid Dynamics) methods. An excellent review of different modelling methods for energy in building is given by Underwood and Yik in their book [1]. Energy simulation in building design is presented by Clarke in [2]. Building performance simulation for design and operation are described in the monograph [3] edited by Hensen and Lambers. Review of different building simulation applications can be found in [4] and [5]. Practical approach to computational fluid dynamics, which is suitable for civil engineers, can be found in [6]. A practical guide of finite element methods for computational fluid dynamics can be found in [7].

All computer codes used for building energy simulations especially these based on computational fluid dynamics are very complicated. Their proper usage requires deep theoretical and practical knowledge. There are two computer codes - Energy2D and Energy3D created by Doctor Cherles Xie which are very simple and user friendly.

\section{Building energy - theoretical background}

The thermal performance of a building is represented by the efficiency with which it uses energy to maintain the thermal comfort for its occupants. In order to calculate this energy

*Corresponding author: r.gajewski@il.pw.edu.pl 
all heat transfer methods are taken into account: thermal conduction, convection and radiation. In thermal conduction the rate of heat flow is governed by the following relationship:

$$
\frac{\Delta Q}{\Delta t}=-\lambda A \frac{\Delta T}{\Delta x}
$$

where $\Delta Q$ is the thermal energy change of the object within time period of $\Delta t, \Delta T$ is the temperature difference across a distance $\Delta x, \lambda$ is the thermal conductivity of the material and $A$ is the area. This relation is also known as Fourier's law of thermal conduction in which we use the concept of heat flux $\Phi$.

$$
\Phi=-\lambda \frac{\Delta T}{\Delta x}
$$

In the process of convection thermal energy passes through a flow of fluid. Convective heat flux is estimated by simple formula

$$
\Phi=h\left(T-T_{\infty}\right)
$$

where $h$ is the convective heat transfer coefficient of a fluid, $T$ is the temperature of the surface and $T_{\infty}$ is the temperature of the fluid. This equation is known as Newton's law of cooling. In the radiation process the energy radiated by an object per unit time is proportional to the fourth power of the absolute temperature

$$
\Phi=\varepsilon \sigma T^{4}
$$

where $\sigma$ is the Stephan-Bolzman constant, $\varepsilon$ is the emissivity of the object's material. This formula is known as Stephan-Bolzman law.

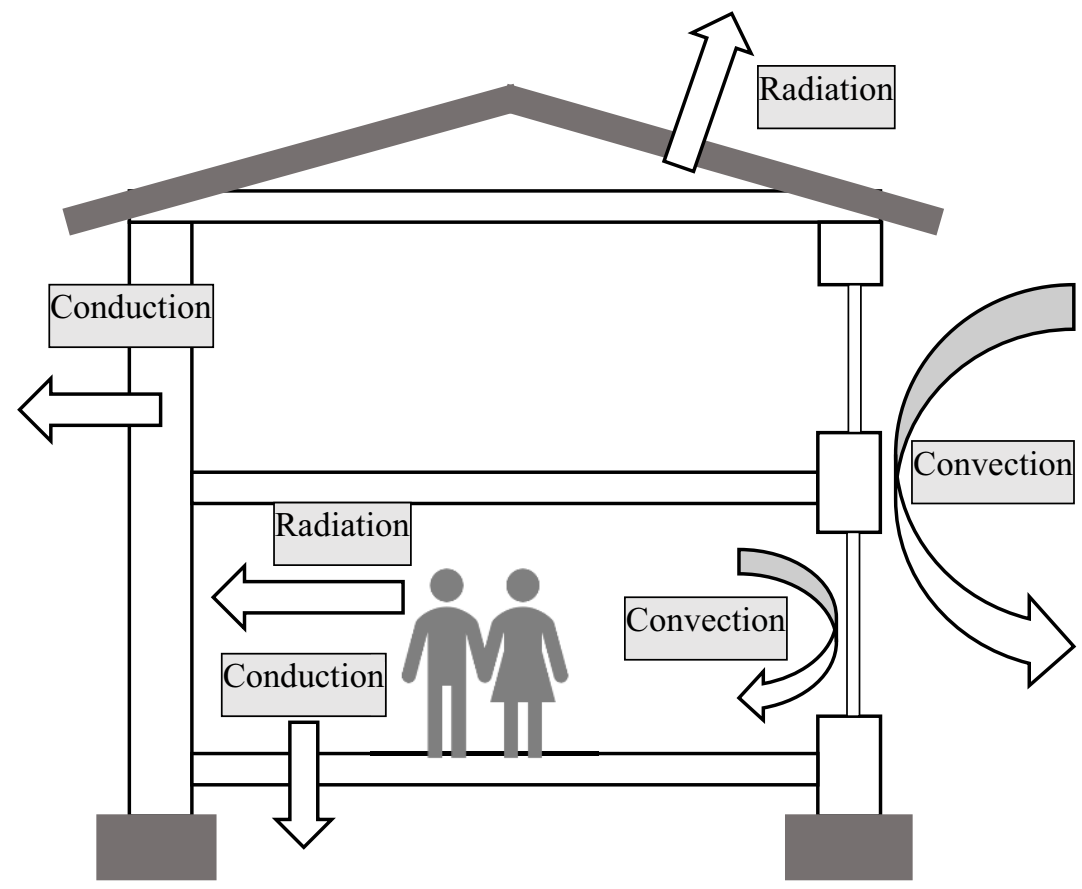

Fig. 1. Heat transfer across the building envelope.

The heat transfer across the building envelope - the shell of a house that separates the inside and outside, should generally be minimized (see Fig. 1). The measure of insulation is 
named $R$-value. It represents the ability to resist heat transfer through the building envelope under given temperature difference. $U$-factor on the other hand represents material's ability to transfer heat.

$$
\Phi=\frac{T_{2}-T_{1}}{R}=U\left(T_{2}-T_{1}\right)
$$

The thermal energy $p_{i}$ gained or lost per unit time through a surface area $A_{i}$ of a building component $i$ at time $t$ is:

$$
p_{i}(t)=A_{i} U_{i}\left[T_{\text {in }}-T_{\text {out }}(t)\right]
$$

The total heat flow across the building envelope is the sum of heat flow through all of its components:

$$
p(t)=\sum_{i} A_{i} U_{i}\left[T_{\text {in }}-T_{\text {out }}(t)\right]
$$

The total quantity of heat that flows across the entire building envelope in a year is the sum of heat flow through all of its components over 365 days:

$$
Q=\sum_{d=1}^{365} \sum_{k=1}^{N}\left|\sum_{i} A_{i} U_{i}\left[T_{\text {in }}-T_{\text {out }}\left(t_{d}+k \Delta\right)\right] \Delta, \quad \Delta=\frac{24 \cdot 60 \cdot 60}{N}\right|
$$

where $N$ is the number of time intervals in which a day is divided for this calculation.

\section{Verification and validation}

In addition to all errors that can arise while performing numerical simulation there are also uncertainties due to improper modelling of physics or incorrect computational design. Verification and validation procedures are used in order to properly assess solution. Both terms have distinctive definitions. As stated in [6] "verification can be defined as a process for assessing the numerical simulation uncertainty and when conditions permit, estimating the sign and magnitude of the numerical simulation error and the uncertainty in that estimated error. This procedure concerns primarily the input parameters used for geometry, initial conditions, and boundary conditions." On the other hand as stated in [6] "validation can be defined as a process for assessing simulation model uncertainty by using benchmark experimental data and when, conditions permit, estimating the sign and magnitude of the simulation modelling error itself." This procedure simply means validating the calculations by establishing a range of physical conditions obtained from the calculations and by performing comparisons of the results from the CFD code with experiments that span the range of conditions.

Both processes were performed for Energy3D code in order to check the quality of models and results of simulations. From a validation perspective, comparative tests will show that Energy3D gives solutions that are reasonable compared to other energy simulation programs. Comparative testing is also useful for input debugging. Energy simulation programs have so many inputs and outputs that the results are often difficult to interpret. In order to compare results with known from literature Building Energy Simulation Test (BESTEST) was used. It was described in many publications [8], [9], [10], [11] [12] and [13]. Sample BESTEST building is shown in Fig. 2. The tests described in ANSI/ASHRAE Standard 140-2001, Standard Method of Test for the Evaluation of Building Energy Analysis Computer Programs (ANSI/ASHRAE 2001) were performed. 


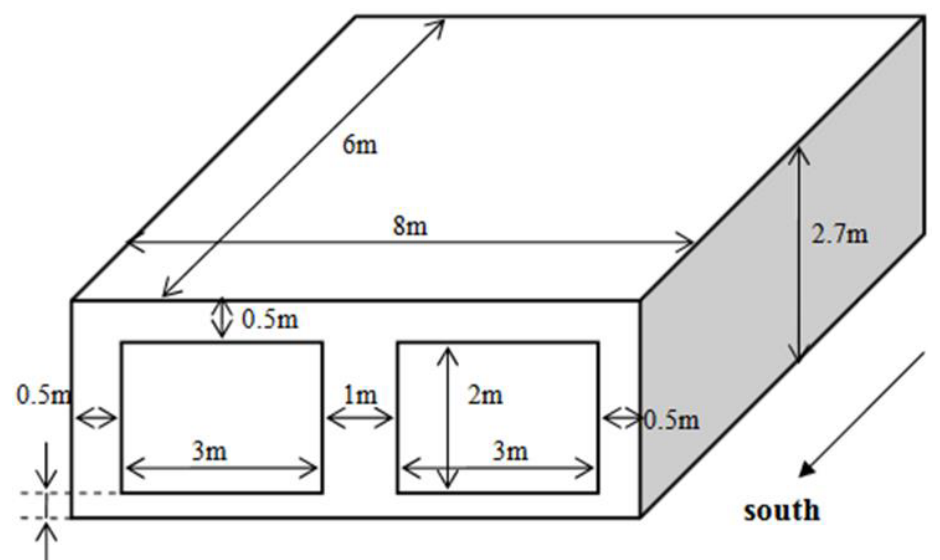

Fig. 2. BESTEST case building 600.

The basic test building is a rectangular single zone ( $8 \mathrm{~m}$ wide $\mathrm{x} 6 \mathrm{~m}$ long $\mathrm{x} 2.7 \mathrm{~m}$ high) with no interior partitions and $12 \mathrm{~m}^{2}$ of windows on the south exposure. The building is of lightweight construction with characteristics as described below in Table 1.

Table 1. Wall Construction (light weight mass).

\begin{tabular}{|c|c|c|c|c|c|c|}
\hline Element & $\begin{array}{c}\mathbf{k} \\
{[\mathbf{W} / \mathbf{m K}]}\end{array}$ & $\begin{array}{c}\text { Thickness } \\
{[\mathbf{m}]}\end{array}$ & $\begin{array}{c}\mathbf{U} \\
{\left[\mathbf{W} / \mathbf{m}^{2} \mathbf{K}\right]}\end{array}$ & $\begin{array}{c}\mathbf{R} \\
{\left[\mathbf{m}^{2} \mathbf{K} / \mathbf{W}\right]}\end{array}$ & $\begin{array}{c}\text { Density } \\
{[\mathbf{k g} / \mathbf{m}]}\end{array}$ & $\begin{array}{c}\mathbf{c}_{\mathbf{p}} \\
{[\mathbf{J} / \mathbf{k g K}]}\end{array}$ \\
\hline Int. Surface Coeff. & & & 8.290 & 0.121 & & \\
\hline Plasterboard & 0.160 & 0.012 & 13.333 & 0.075 & 950 & 840 \\
\hline Fiberglass Quilt & 0.040 & 0.066 & 0.606 & 1.650 & 12 & 840 \\
\hline Wood Siding & 0.140 & 0.009 & 15.556 & 0.064 & 530 & 900 \\
\hline Ext. Surface Coeff. & & & 29.300 & 0.034 & & \\
\hline Overall, air-to-air & & & 0.514 & 1.944 & & \\
\hline
\end{tabular}

Charts comparing Energy3D results with other whole building energy simulation programs are in Fig. 3. More results can be found in B.Sc. thesis prepared by Pieniążek [14].

\section{Qualitative and quantitative analysis}

Energy3D can be used for both qualitative and quantitative analysis. One can measure and compare such values as:

- Effects of the house size on the energy use;

- Effects of the house shape on the energy use;

- Effects of roof insulation on the energy use of a house;

- Effects of roof colour on the energy use of a house;

- Effects of solar heat gain coefficients of windows on the energy use of a house;

- Effects of orientation on the energy use of a house; 
- Effects of the thermostat setting on the energy use of a house;

- Energy use of a house at different locations;

- Effects of environment albedo on the energy use of a house;

- Effects of sun-facing windows on the energy use of a house;

- Effects of trees on the air conditioning of a house;

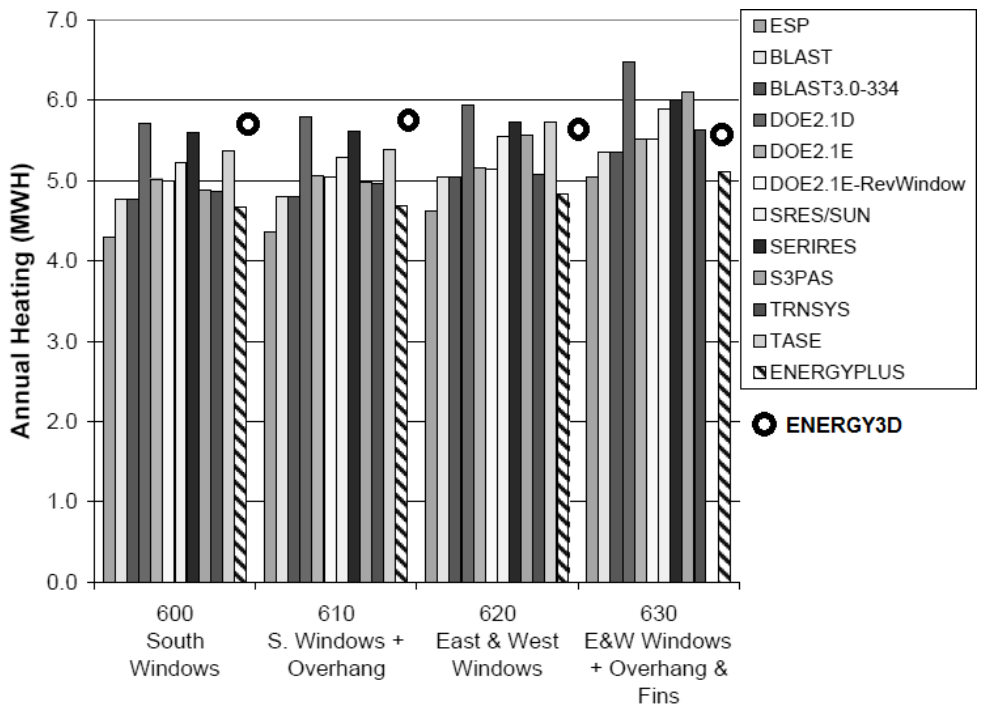

Fig. 3. Comparison of Energy3D results with other whole building energy simulation programs.

Results presenting energy use of a house at different locations are in Fig. 4. Differences in climate in Poland are relatively small but annual energy for Białystok (solid line without markers) and Wrocław differ significantly (qualitative analysis).

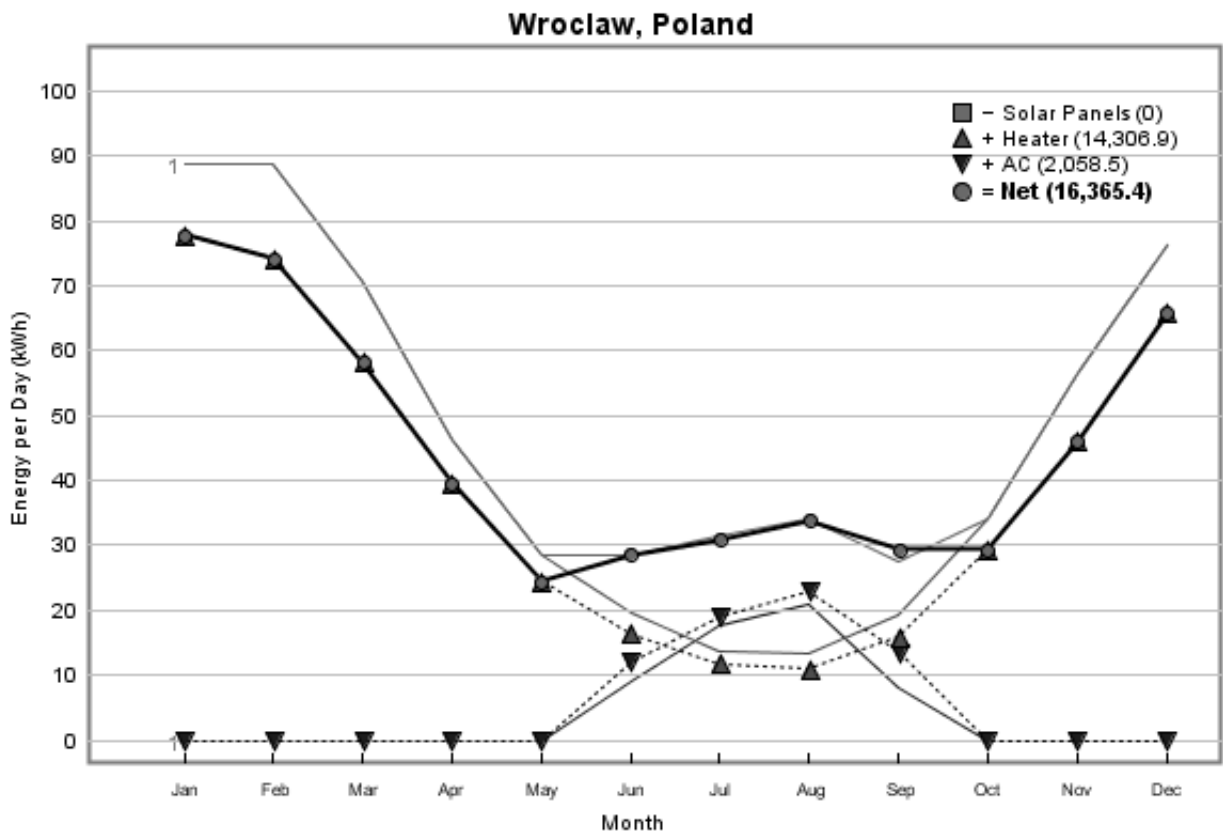

Fig. 4. Annual energy for sample building located in Białystok and Wrocław. 


\section{Final conclusions}

This paper presents validation and verification of Energy3D code used for building energy modelling and simulations. This simple computer code proved to be an excellent tool for qualitative and quantitative analysis of buildings. Such a program can be an excellent part of a computer supported design environment [2] which takes into account also energy considerations.

This research was not sponsored by any grant or authorities. This research was done just for pleasure and satisfaction.

\section{References}

1. C. Underwood, F. Yik, Modelling Methods for Energy in Buildings, 1 edition (WileyBlackwell, Oxford Malden, MA, 2004)

2. J. Clarke, Energy Simulation in Building Design, 2 edition (Routledge, Oxford, 2001).

3. J. L. M. Hensen and R. Lamberts, editors, Building Performance Simulation for Design and Operation (Routledge, London; New York, 2011)

4. M. Baratieri, V. Corrado, A. Gasparella, and F. Patuzzi, editors, Building Simulation Applications BSA 2013 (Bozen-Bolzano University Press, Bozen-Bolzano, 2013)

5. M. Baratieri, V. Corrado, A. Gasparella, and F. Patuzzi, editors, Building Simulation Applications BSA 2015 (Bozen-Bolzano University Press, Bozen-Bolzano, 2015)

6. J. Tu, G. Heng, C. Liu, Computational Fluid Dynamics, Second Edition: A Practical Approach, 2 edition (Butterworth-Heinemann, Amsterdam, 2012)

7. D. Kuzmin, J. Hamalainen, Finite Element Methods for Computational Fluid Dynamics: A Practical Guide (SIAM, 2014)

8. R. H. Henninger, M. J. Witte, EnergyPlus Testing with ANSI/ASHRAE Standard 1402001 (BESTEST) (Lawrence Berkeley National Laboratory, Berkeley, California, 2004)

9. R. Judkoff, J. Neymark, International Energy Agency Building Energy Simulation Test (BESTEST) and Diagnostic Method (National Renewable Energy Lab., Golden, CO (US), 1995)

10. R. Judkoff, J. Neymark, Standard Method of Test for the Evaluation of Building Energy Analysis Computer Programs (American Society of Heating, Refrigerating and Air-Conditioning Engineers, Inc., 2004)

11. R. Judkoff and J. Neymark, in (Chambery, France August 25-28, 2013, 2013).

12. M. Woloszyn, C. Rode, IEA Annex 41, MOIST-ENG Subtask 1 - Modelling Principles and Common Exercises (2007)

13. T. Soubdhan, T. A. Mara, H. Boyer, A. Younes, World Renew. Energy Congr. VI (Pergamon, Oxford, 2000)

14. P. Pieniążek, Computer Simulation of Building Energy (B.Sc. Thesis, Warsaw University of Technology, Faculty of Civil Engineering, 2016) 